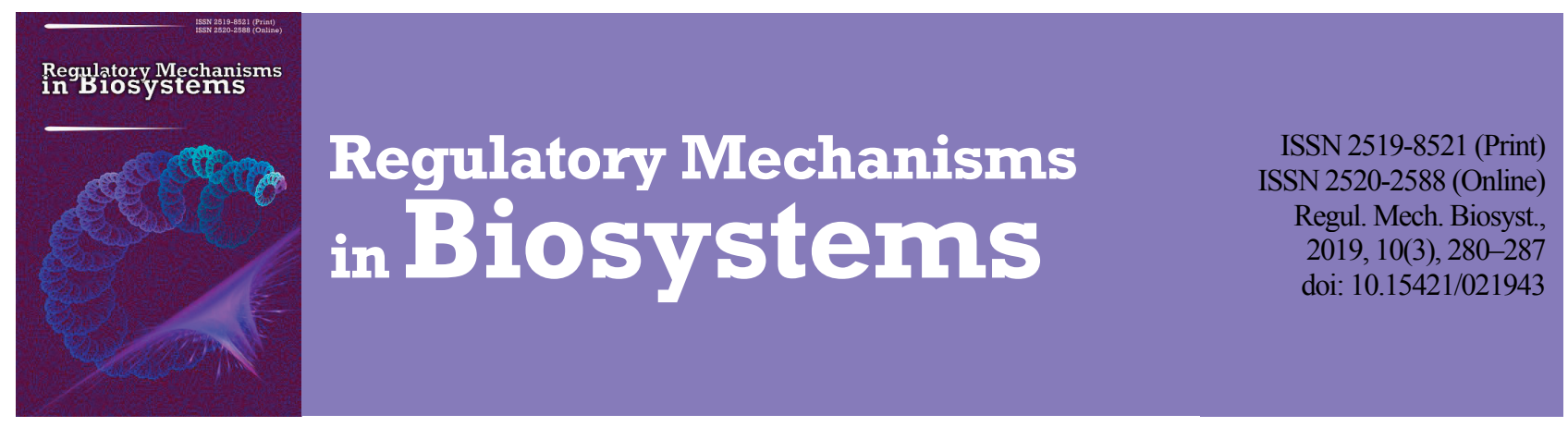

\title{
Power spectrum and coherence of electroencephalograms of young people with the use of mnemotechnics
}

\author{
Y. Usenko, O. Severynovska, I. Kofan, I. Dregval, O. Znanetska \\ Oles Honchar Dnipro National University, Dnipro, Ukraine
}

Article info

Received 29.06.2019

Received in revised form 22.07.2019

Accepted 25.07.2019

\begin{abstract}
Usenko, Y., Severynovska, O., Kofan, I., Dregval, I., \& Znanetska, O. (2019). Power spectrum and coherence of electroencephalograms of young people with the use of mnemotechnics. Regulatory Mechanisms in Biosystems, 10(3), 280-287. doi:10.15421/021943
\end{abstract}

Oles Honchar Dnipro National University, Gagarin ave., 72 ,

The increase of external information and the need for processing of large information arrays has been leading to the search for mechanisms of thinking in mental activity, as well as new methods of data protection and reproduction. Power spectrum and coherence of electroencephalograms (EEG) during memorizing of foreign words has been analyzed in many ways: in the usual one with the help of mnemotechnics. The research was conducted during the ovarian phase of the cycle of 11 female students aged 18-20. Registration of EEG activity was carried out according to the international system of H. Jasper,"10-20". The process of recollection of associative information led to the decrease in the power spectrum of the EEG in the alpha range in the frontal and temporal loci of the left hemisphere and the prefrontal sections of both hemispheres, in the beta range it was probable only in $\mathrm{T} 6$ zone of beta 2 range, in the delta range it was in the prefrontal, posterior lower-frontal and posttemporal loci of both hemispheres, in the central, parietal and occipital regions of the left hemisphere, as well as in the anteriofrontal zone of the right hemisphere, in the theta-range - in the prefrontal and posterior lowerfrontal regions of both hemispheres and in the posttemporal and occipital loci of the left hemisphere. Synchronization in the delta range is the reflection of the processes of figural information processing and manipulation. With the increase of attention concentration, the synchronization was observed in the theta range in the anteriofrontal and F4-P4 zones. Interhemispheric functional and symmetrical bonds in the alpha and beta ranges indicate the involvement of the corpus callosum in the process of memorizing foreign words, which facilitates their faster, more correct and easier reproduction, especially with the use of associative images. The decrease of power spectrum in the delta and theta ranges showed that less effort was required to reproduce associative information than to mention unsupported images of foreign words. The effective use of the association method is realized by reduction of the power spectrum of the waves in the alpha range in the frontal and temporal loci of the left hemisphere and the prefrontal sections of both hemispheres, which indicates the activation of mental activity in these zones in the processes of maintaining and reproducing associative information.

Keywords: cerebral bioelectric activity; a foreign language; associations; associative thinking.

\section{Introduction}

Memory is the basis for the cognition of the surrounding world, and in the process of individual development of a person it is the basis for the formation of personality. Human memory is a link between the past, the present and the future (Schacter et al., 2007). The loss of the ability to remember past events is, to a certain extent, the loss of self. In the functioning of memory, the network interaction of the medial temporal zone with cortical structures of the brain plays a significant role (Greicius et al., 2003; Vincent et al., 2006). The network approach lies in the understanding of Alzheimer's disease and other neurodegenerative diseases (Seeley et al., 2009; Montembeault et al., 2019).

For better understanding of the network structure that supports memory, in this article we are focusing not on the memory loss, but on the increasing of its volume. The winners of the annual World Memory Championships regularly show an amazing ability to memorize hundreds of words, numbers, and other pieces of abstract information in a few minutes (Foer, 2011). Similar skills are not related to the anatomy of the brain and cognitive peculiarities, they are acquired as a result of mastering mnemonic strategies (Maguire et al., 2003; Dresler \& Konrad, 2013; Dresler et al., 2017), which can be mastered even by people with Alzheimer's disease and other cognitive disorders (Hampstead et al., 2019; Simon et al., 2019). Although the loci method, based on the known recollections of imaginary routes during information encoding (Khalid Khan, 2016), is one of the most prominent and widespread me- thodologies, there are other methods. In general, mnemotechnics is a set of techniques that facilitate the memorization of numbers, symbols or new words by creating artificial associations and relationships between certain images. If the material is memorized in a relationship with something well known, it will be remembered and retained in memory for a long time and can be easily retrieved from it with the help of verbal or visual associations (Lopatin, 2014; Jeffrey, 2017). This method involves both auditory and visual channels and related brain zones (Mastropieri, 1988; Thaut et al., 2014).

According to the paradigm of the levels of information processing (Craik \& Lockhart, 1972), any information is subjected to a number of analytical procedures of different degrees of complexity. Memory strength depends on the depth of information processing: the deeper the analysis is, the better the memorization and the easier subsequent reproduction are. According to the concept of Craik \& Lockhart (1972), there are three levels of analysis, and the establishment of associative relationships with other significant units of information that are already stored in memory is the deepest among them. Memorizing which is based on such associative relationships provides the strongest trace in memory (Eichenbaum, 2017). Creation of figurative associations, use of associative mental maps, and radiant schemes can simplify the study of many disciplines. For example, the study of natural sciences is impossible without the use of diagrams, tables, drawings, etc., and the remembering of complex mechanisms of functioning of biological systems requires the use of logic and associative thinking, which allows one to approach 
the study of biology in a comprehensive way and have a coherent and versatile conception of a living organism, as well as establish cause and effect relationships, pay attention to internal and external factors. With the help of various techniques of mnemotechnics, you can effectively study foreign vocabulary. Therefore, in order to improve the efficiency and to facilitate the study of English (or any foreign) words, it is worthwhile to use the methods of mnemotechnics. Although numerous behavioural studies have demonstrated the effectiveness of mnemonic strategies, such as the method of loci (Nicholson, 2006; Worthen \& Hunt, 2011), data on brain changes, which are the basis of mnemotechnics, are rather rare (Maguire et al., 2003; Kamel \& Malik, 2014; Fellner et al., 2016; Dresler et al., 2017). EEG mapping plays an important role in establishing mechanisms for the formation of "memory chains" in the brain. If the words are capable of causing the corresponding visual effects, it is a guarantee of keeping them in the long-term memory. It is in this way that the mnemonics enriches the vocabulary. The high power of EEG signals in the alpha- and beta bands is responsible for the increase in attention while studying (Tellamekala \& Rafi, 2016). Therefore, in order to find out the changes of the basic function of the brain using mnemonic strategies, we investigated the interconnections of cerebral cortex structures related to memory and the processing of visual and auditory information during the perception and memorization of English words.

The purpose of this work was to study the individual characteristics of cerebral bioelectric activity in students during the usual and associative (mnemonic) ways of memorizing of professional foreign words.

\section{Materials and methods}

The research involved 11 female students aged 18-20. All the participants volunteered to take part in the study, the conditions of which they were previously familiarized with. The participants of the research gave their consent to the voluntary participation in the experiment, which was approved by the Ethics Commission of the faculty. To determine the physiological state of the subjects at the time of the study, the phases of the menstrual cycle were taken into account. The studies were conducted during the ovarian phase of the cycle. None of the participants suffered from any neurological or psychiatric illnesses, or complained of physical exhaustion or sleepiness. During the study, the subjects were in a dark, well-ventilated room, without any unwanted noise, sitting in comfortable armchairs.

In the course of recording of electrical activity of the brain, a background recording of EEG in a resting state with closed and open eyes was being recorded. The participants were asked to remember 30 unfamiliar English words in a way familiar to them. The students were repeatedly shown cards with these words and the translation of the words, then the EEG was registered in the course of memorising the words. After that, the participants were asked to memorize 30 other unfamiliar English words in an associative way by imagining a clear image of each word. If there were any difficulties with the formation of the association, the participants were offered a ready image for memorization. Then the EEG was recorded during memorization of the words. In the process of mental activity, the registration and primary analysis of EEG activity was carried out with the help of the hardware and software complex DX NT32.V19 (manufacturer "DX-Complex", LTD, Kharkov, Ukraine). EEG were recorded from 16 standard divisions of the left and right hemispheres : symmetric prefrontal ones - Fp1 and $\mathrm{Fp} 2$; frontal ones $\mathrm{F} 3$ and $\mathrm{F} 4$; central ones $-\mathrm{C} 3$ and $\mathrm{C} 4$; parietal ones $-\mathrm{P} 3$ and P4; occipital ones - $\mathrm{O} 1$ and $\mathrm{O} 2$; temporal ones - F7, F8, T3, T4, T5, T6, according to the international system of $\mathrm{H}$. Jasper "10-20". The combined electrodes AV, which were fixed on the ears, were the referent. A neutral electrode was located in the area of the forehead. During the Fourier implementation, the analysis period was $500 \mathrm{~ms}$. The sampling frequency of the transducer analog was $2 \mathrm{~ms}$; the common-mode input impedance was more than $100 \mathrm{MOm}$. High frequency filters were set at $50 \mathrm{~Hz}$, low ones - at $0.5 \mathrm{~Hz}$. The limits of the possible relative error during the measurement of voltage and time intervals of electroencephalographic signals were $\pm 5 \%$. The removal of EEG artefacts was carried out by the expert method in the viewing mode of the recording, accord- ing to the software of the device. The analysis of changes caused in the rhythmic activity of the brain (event related desynchronization / synchronization - ERD/ERS) was one of the information-bearing methods for studying the processes of mental activity. The induced desynchronization (ERD) was defined as related to the event of decrease compared with the pre-stimulation level, the amplitude of the rhythm of a certain frequency, and the induced synchronization (ERS) was defined as related to the event of amplitude increase (Pfurtscheller \& Lopes da Silva, 1999). Synchronous work of brain sections was determined by means of correlation analysis. For each type of coherent connection in each frequency range the average values were calculated. A coherent connection with a value of not less than $0.6(0.60-0.69)$ was considered as a connection of medium level, with a value of 0.7 or more - as a high-level connection (Rebrova, 2006).

Statistical data analysis was performed using the Statistica 6.0 package (StatSoft Inc. USA, 2001). Using the tests on normality by Kolmogorov and Smirnov and by Lilliefors, it has been found that the data processing has to be carried out using non-parametric methods. The experimental data from each group of studies were presented as median and lower and upper quartiles (Me $[25 ; 75])$. To compare the dependent samples, the Wilcoxon T-criterion was used. In comparison of the functional states of the subjects, only significant differences in the parameters of the EEG were analyzed $(\mathrm{P}<0.05)$.

\section{Results}

The comparison of strategies for memorizing of foreign words with the state of open eyes (Fig. 1) showed that for the usual way of memorizing of foreign words in the delta-frequency range there was an increase of power spectrum in a large number of divisions.
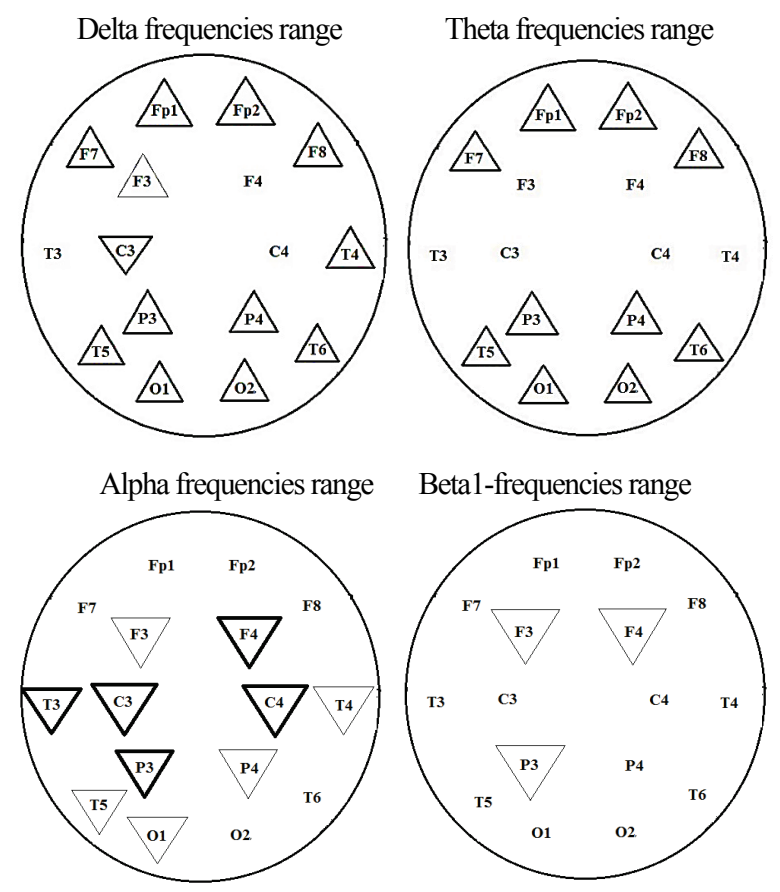

Fig. 1. Sections of probable changes in the SP of high-frequency components of EEG of the students when foreign words were memorized in the usual way $(n=44)$ compared with the background state of the open eyes ( $n=44$ ), the significance level $\mathrm{P}<0.05$ according to the Wilcoxon

criterion (thin line), the significance level $\mathrm{P}<0.01$ according to the Wilcoxon criterion (thick line). A triangle with a top down indicates a decrease, and a triangle with a top up $\mathrm{i}$ - about an increase of the SP frequencies of the alpha, beta1- and beta2-ranges

A significant increase $(\mathrm{P}<0.01)$ was recorded in the prefrontal, posterior lower-frontal, parietal, posttemporal and occipital regions of both hemispheres, and in the anteriofrontal locus of the right hemisphere. A less significant increase was observed in the frontal region F3 of the left hemisphere $(\mathrm{P}<0.05)$. In addition, there was a significant 
decrease of power spectrum in the central locus $\mathrm{C} 3$ of the left hemisphere $(\mathrm{P}<0.01)$. A bilateral increase of power spectrum in the range of theta frequencies under the usual memorization was noticed in the prefrontal, posterior lower-frontal, parietal, posttemporal and occipital regions $(\mathrm{P}<$ 0.01). The comparison of memorization of foreign words with the help of usual method for the students, with the state of open eyes, showed a decrease of power spectrum in the medial, anteriofrontal regions, in the posttemporal (T5) and occipital (O1) loci of the cerebral cortex in the range of alpha frequencies. The most significant decrease $(\mathrm{P}<0.01)$ was observed in the central zones, frontal F4, parietal P3 and anteriofrontal T3 regions. The decrease of power spectrum in the beta- 1 range was noted in the frontal areas of both hemispheres and in the parietal zone of the left hemisphere $-\mathrm{P} 3(\mathrm{P}<0.05)$.

Using the usual method of memorization did not cause any probable changes in power spectrum in the range of beta2-frequencies.

The use of the associative method in memorizing foreign words, in comparison with the background state (open eyes) (Fig. 2), caused an increase of power spectrum similar to the usual way in the range of delta frequencies in the parietal, posttemporal, occipital regions of both hemispheres, in the posterior lower-frontal area of the left hemisphere F7 $(\mathrm{P}<0.01)$, and caused a less significant increase in the posterior lower-frontal locus of F8 in the right hemisphere $(\mathrm{P}<0.05)$.

Delta frequencies range

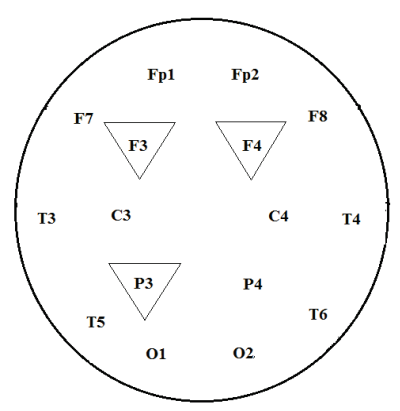

Alpha frequencies range

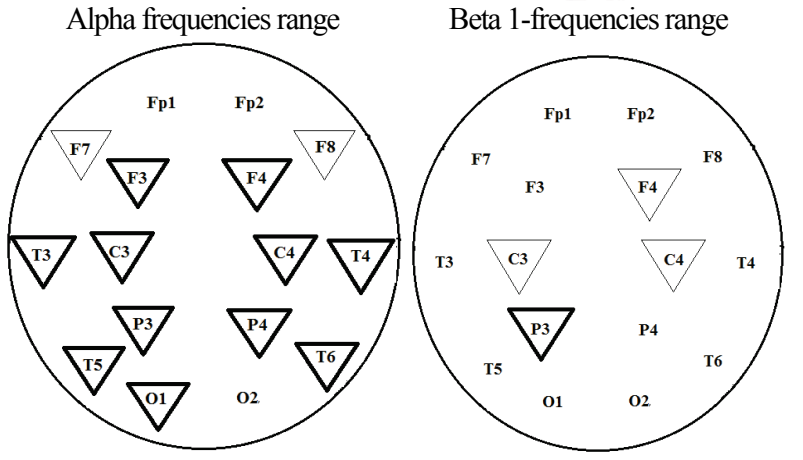

Beta 2-frequencies range

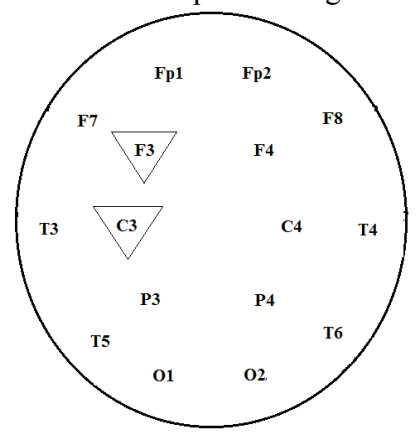

Fig. 2. Sections of probable changes in the SP of high-frequency components of EEG of the students when foreign words were memorized in an associative way $(\mathrm{n}=44)$ compared with the background state of open eyes $(\mathrm{n}=44)$, the significance level $\mathrm{P}<0.05$ according to the Wilcoxon criterion (thin line), the significance level $\mathrm{P}<0.01$ according to the Wilcoxon criterion (thick line); a triangle with a top down indicates a decrease, and a triangle with a top up - an increase of the SP frequencies of the alpha, beta $_{1}-$, and beta $_{2}$-ranges
The features caused by the creation of associations were reflected in a significant decrease in power spectrum in the prefrontal sections of both hemispheres $(\mathrm{P}<0.01)$, as well as in its slight increase in the central zone $\mathrm{C} 3$ of the left hemisphere $(\mathrm{P}<0.05)$.

In the theta frequencies range with the use of the associative method, there was an increase in power spectrum in a smaller number of brain regions than with the use of the usual way of memorizing. The changes were recorded in the prefrontal and parietal zones of both hemispheres, in the posterior $\mathrm{T} 6$ and occipital $\mathrm{O} 2$ loci of the right hemisphere. The most significant increase was observed in the parietal zone of the left hemisphere $\mathrm{P} 3(\mathrm{P}<0.01)$.

In the range of alpha frequencies, using the associative method of memorizing foreign words, there was a decrease in power spectrum in more regions of the brain than with the help of the usual way of memorizing. The similar changes were observed in the medial, anteriofrontal regions of both hemispheres and the posttemporal and occipital regions of the left hemisphere (the corresponding leads were T5 and O1). In contrast to the usual memorization, with the associative one there was a decrease in power spectrum in the posterior lower-frontal areas (F7 and F8) and the posttemporal locus of the right hemisphere, T6 lead. All the areas were characterized by significant $(\mathrm{P}<0.01)$ decreases in power spectrum, except for $\mathrm{F} 7$ and $\mathrm{F} 8$ loci $(\mathrm{P}<0.05)$.
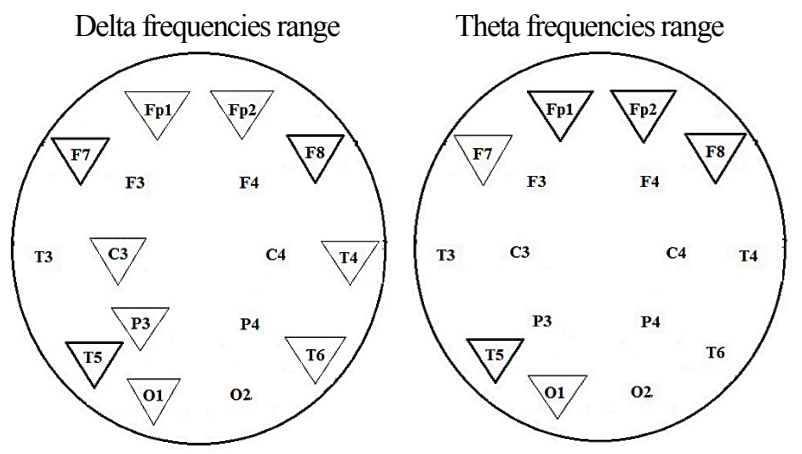

Alpha frequencies range

Beta 2-frequencies range

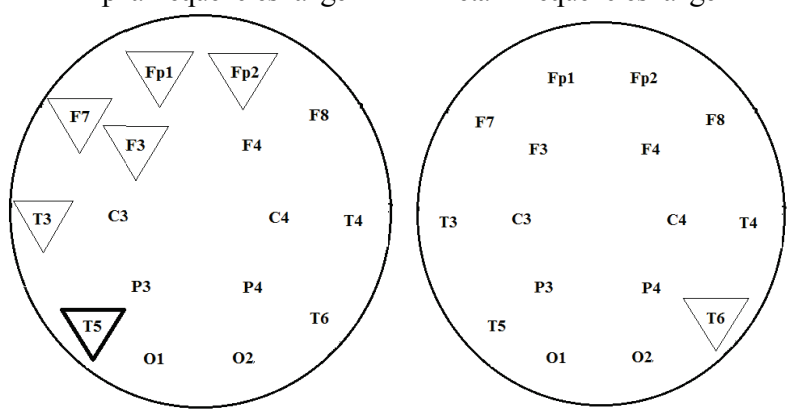

Fig. 3. Sections of probable changes in the high-frequency EEG components of the students when foreign words were memorized in the associative way $(n=44)$ compared with memorizing foreign words in the usual way $(\mathrm{n}=44)$, the significance level $\mathrm{P}<0.05$ according to the Wilcoxon criterion (thin line), the significance level $\mathrm{P}<0.01$ according to the Wilcoxon criterion (thick line); a triangle with a top down indicates a decrease, and a triangle with a top up - an increase of the SP frequencies of the alpha-, beta $_{1}-$, and beta 2 -ranges

The decrease of power spectrum in the betal-frequencies range during the use of the associative method was fixed in the central regions, the frontal area of the right hemisphere (F4) and the parietal zone of the left one (P3). In the latter locus the decrease was the most probable $(\mathrm{P}<$ 0.01 ). Both with the creation of associations, and with the use of the usual way of memorizing foreign words, there was a decrease in power spectrum in the frontal area of the right hemisphere (F4) and the parietal zone of the left one (P3). In the range of beta2-frequencies, the creation of associations caused a decrease in power spectrum in the frontal (F3) and central $(\mathrm{C} 3)$ regions of the left hemisphere $(\mathrm{P}<0.05)$. The associative memorization of words in comparison with the usual way (Fig. 3) led to the decrease of power spectrum in the range of delta frequencies. Minor changes were observed in the prefrontal sections of both hemis- 
pheres, in the central $(\mathrm{C} 3)$, parietal $(\mathrm{P} 3)$ and occipital $(\mathrm{O} 1)$ regions of the left hemisphere, in the anteriofrontal (T4) and posttemporal (T6) loci of the right hemisphere $(\mathrm{P}<0.05)$. A significant decrease in power spectrum was recorded in the posterior lower-frontal areas of both hemispheres and the posttemporal (T5) zone of the left hemisphere $(\mathrm{P}<0.01)$.

In the theta frequencies range, the differences between associative and conventional memorization methods revealed a significant decrease in power spectrum in the prefrontal sections of both hemispheres, in the posterior lower-frontal (F8) zone of the right and posttemporal (T5) regions of the left hemisphere, as well as in less significant power spectrum reduction in the posterior lower-frontal (F7) and occipital (O1) loci of the left hemisphere.

The use of the association method in comparison with the usual way of memorizing foreign words led to a decrease in the power spectrum of waves in the range of alpha frequencies, mainly in the left hemisphere. The reductions were observed in the prefrontal areas of both hemispheres (Fpl and Fp2), frontal (F3) and temporal zones of the left hemisphere (F7, T3, T5). The most significant decrease was recorded in the posttemporal locus of the left hemisphere (T5) $(\mathrm{P}<0.01)$. In the

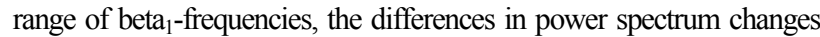
between the associative and conventional methods of memorizing words were not observed. The decrease in power spectrum of beta 2 -frequencies range occurred in the posttemporal locus of the right hemisphere (T6, $\mathrm{P}<0.05$ ) during the creation of associations. While memorizing the words in the usual way in comparison with the background recording (open eyes), in the delta range (Fig. 4a), the inter-hemisphere diagonal bonds between the posterior lower-frontal area of the left hemisphere and the temporal regions of the right hemisphere, respectively F7-T4 and F7-T6, were recorded. In addition, short inner-hemispherical bonds were formed in the posterior part of the right hemisphere, among which a high degree of coherence was observed (P4-T6).

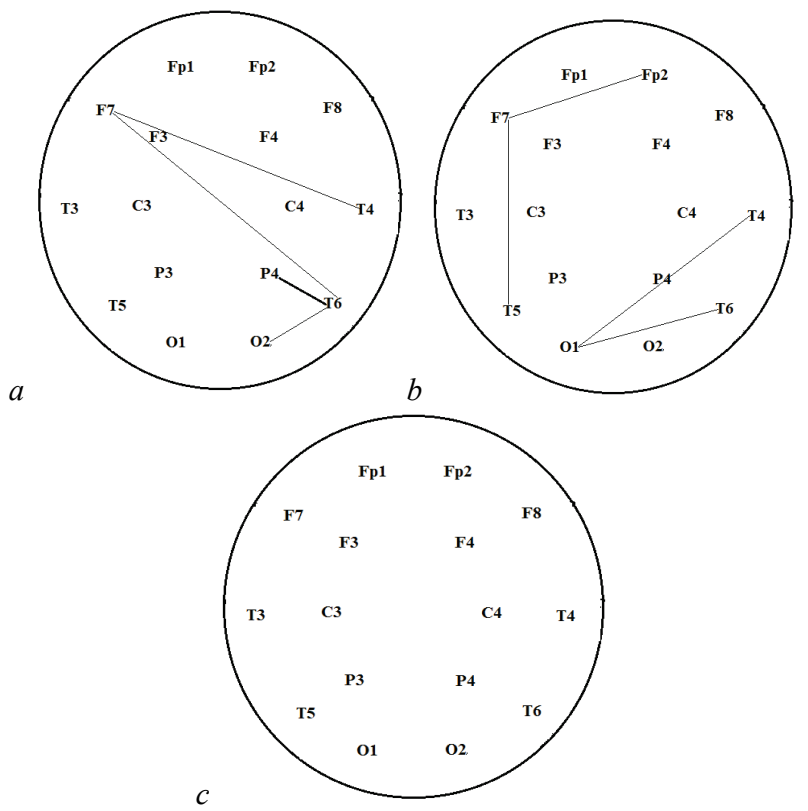

Fig. 4. Probable functional bonds of the cerebral cortex in the deltarange of the students $(n=44): a$ - the usual memorization of foreign

words compared with the background recording (open eyes);

$b$ - the associative memorization of foreign words in comparison with the background recording (open eyes); $c$ - the associative memorization of foreign words compared with the usual way; thin line - coherent bonds of average degree $(\mathrm{K}=0.60-0.69, \mathrm{P}<0.05)$, thick line -

coherent bonds of high degree $(\mathrm{K}=0.70-0.95, \mathrm{P}<0.001)$

Using the associative method of memorizing (Fig. 4b), the innerhemispherical long bond F7-T5 was observed. In addition, inter-hemispherical diagonal bonds, between the occipital area of the left hemisphere and the temporal zones of the right hemisphere (O1-T4 and O1T6), as well as the bond Fp2-F7, were formed. When comparing the associative method with the usual one, in the delta-range the synchro- nicity of waves was not detected (Fig. 4c). The memorizing of foreign words in the usual way for the students, in comparison with the background recording (open eyes), in the theta range (Fig. 5a) caused the appearance of a short inner-hemispherical bond $\mathrm{P} 4 \mathrm{O} 2$ in the posterior part of the right hemisphere. Besides, there was an inter-hemispherical bond between the symmetric posttemporal loci T5-T6.

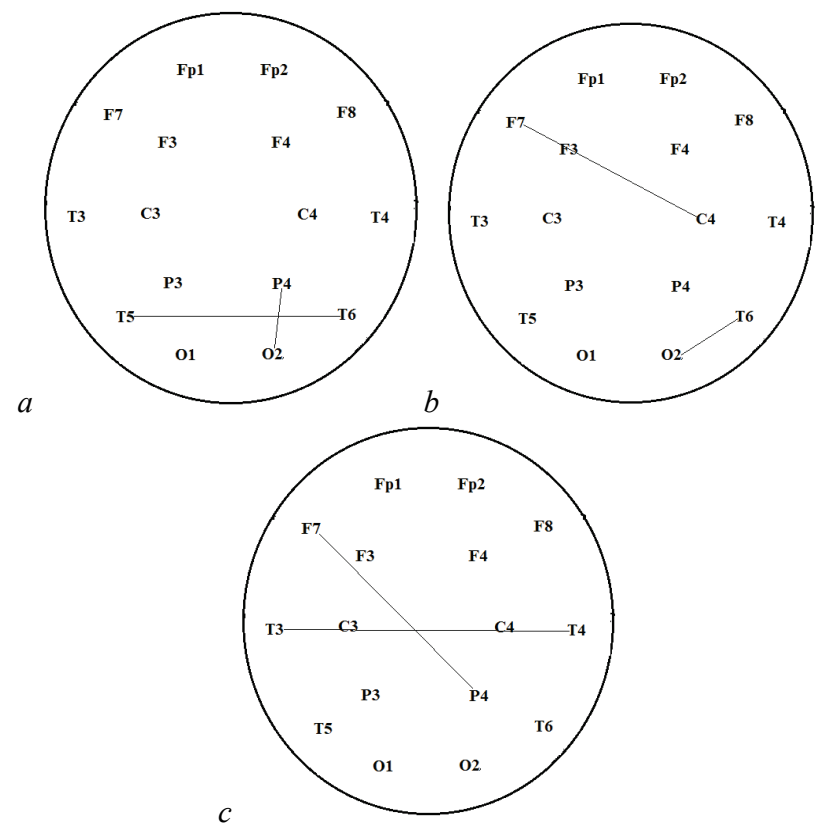

Fig. 5. Probable functional bonds of the cerebral cortex in the theta range of the students $(n=44): a$ - the usual memorization of foreign words compared with the background recording (open eyes); $b$ - the associative memorization of foreign words compared with the background recording (open eyes); $c$ - the associative memorization of foreign words compared with the usual way; thin line - coherent bonds of average degree $(\mathrm{K}=0.60-0.69, \mathrm{P}<0.05)$, thick line coherent bonds of high degree $(\mathrm{K}=0.70-0.95, \mathrm{P}<0.001)$

Using the associative method (Fig. 5b), the inter-hemispherical diagonal bond F7-C4 and the short inner-hemispherical O2-T6 bond in the posterior part of the right hemisphere were recorded. During the associative memorization (Fig. $5 \mathrm{c}$ ), the inter-hemispherical diagonal bond F7-C4 and the short inner-hemispherical bond $\mathrm{O} 2-\mathrm{T} 6$ in the posterior region of the right hemisphere were recorded. The associative memorization, unlike the usual one, was accompanied by creation of the interhemispherical diagonal bond F7-P4 and inter-hemispherical long bond T3-T4 between symmetric leads.

When memorizing words in the usual way, compared with the background recording (open eyes), in the alpha-range (Fig. 6a) only one inner-hemispherical long bond in the left hemisphere between the frontal F3 and posttemporal T5 zones was noted (Fig. 6a) $(\mathrm{P}<0.05)$.

During the associative memorization of foreign words a bond similar to the above-mentioned (F4-T6), but in the opposite hemisphere (Fig. 6b), was observed. In addition, a short inter-hemispherical synchronization between the $\mathrm{O} 1-\mathrm{O} 2$ points in the occipital part of cerebral cortex was formed, which indicates the processing of images in the visual areas of both hemispheres and the involvement of the right hemisphere loci to the processes of memorizing. The associative memorization, unlike the usual one (Fig. 6c), caused the appearance of inter-hemispherical long (F7-F8) and short (C3-C4) bonds and an inter-hemispherical diagonal bond (C3-O2). When memorizing words in the usual way, in comparison with the background recording (open eyes), there was no synchronicity of waves in the beta-1 range (Fig. 7a). In associative memorization (Fig. 7b), there appeared inner-hemispherical long (Fp2-T4) and short (T4-T6) probable bonds $(\mathrm{P}<0.05)$ in the frontal-temporal zones of the right hemisphere. The associative memorization, unlike the usual one (Fig. 7c), was accompanied by the emergence of a large number of bonds, most of which were inter-hemispherical diagonal. In memorizing words in the usual way, compared with the background re- 
cording (open eyes), in the beta2-range (Fig. 8a), probable inter-hemispherical diagonal (F4-P3) and inner-hemispherical long (F8-T6) bonds in the right hemisphere were recorded. In addition, there was an interhemispherical short bond between the symmetric O1-O2 loci, which indicates the simultaneous operation of the visual zones of both hemispheres when memorizing.

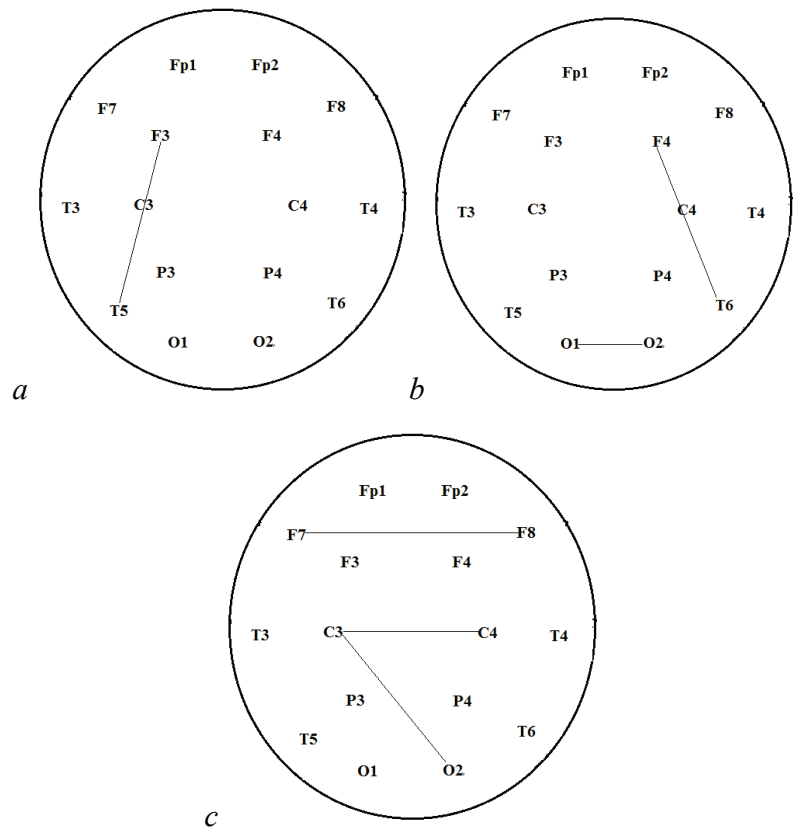

Fig. 6. Probable functional bonds of the cerebral cortex in the alpha range of the students $(\mathrm{n}=44): a$ - the usual memorization of foreign words compared with the background recording (open eyes); $b$ - the associative memorization of foreign words in comparison with the background recording (open eyes); $c$ - the associative memorization of foreign words in comparison with the usual way; thin line - coherent bonds of average degree $(\mathrm{K}=0.60-0.69, \mathrm{P}<0.05)$, thick line coherent bonds of high degree $(\mathrm{K}=0.70-0.95, \mathrm{P}<0.001)$

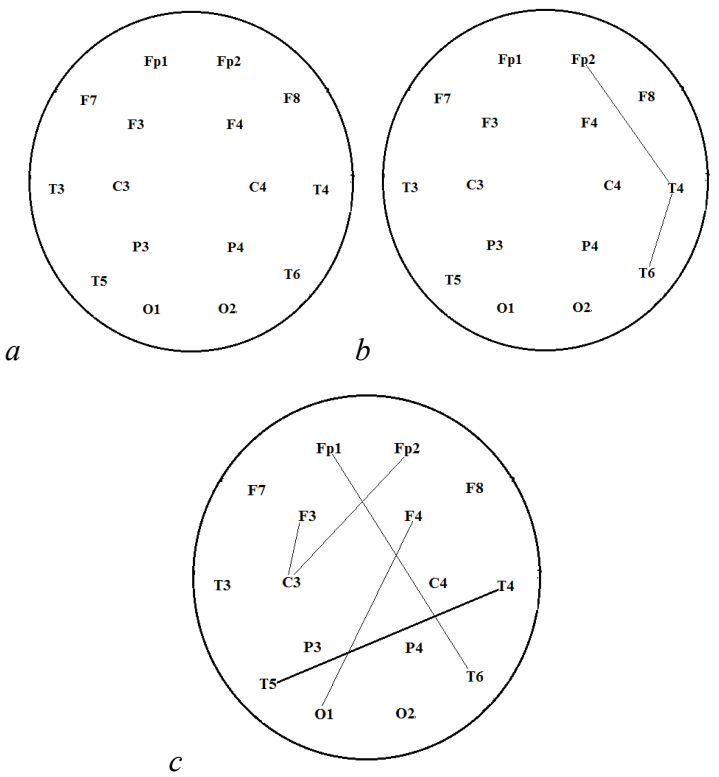

Fig. 7. Possible functional bonds of the cerebral cortex in the beta ${ }_{1}$ range of the students $(\mathrm{n}=44): a$ - the usual memorization of foreign words compared with the background recording (open eyes); $b$ - the associative memorization of foreign words in comparison with the background recording (open eyes); $c$ - the associative memorization of foreign words in comparison with the usual way; thin line - coherent bonds of average degree $(\mathrm{K}=0.60-0.69, \mathrm{P}<0.05)$, thick line - coherent bonds of high degree $(\mathrm{K}=0.70-0.95, \mathrm{P}<0.001)$
When memorizing and storing information in the associative way (Fig. 8b), the inter-hemispheric long diagonal bond between the posterior lower-frontal area of the right hemisphere (point F8) and the parietal area of the left one (point P3) was recorded.

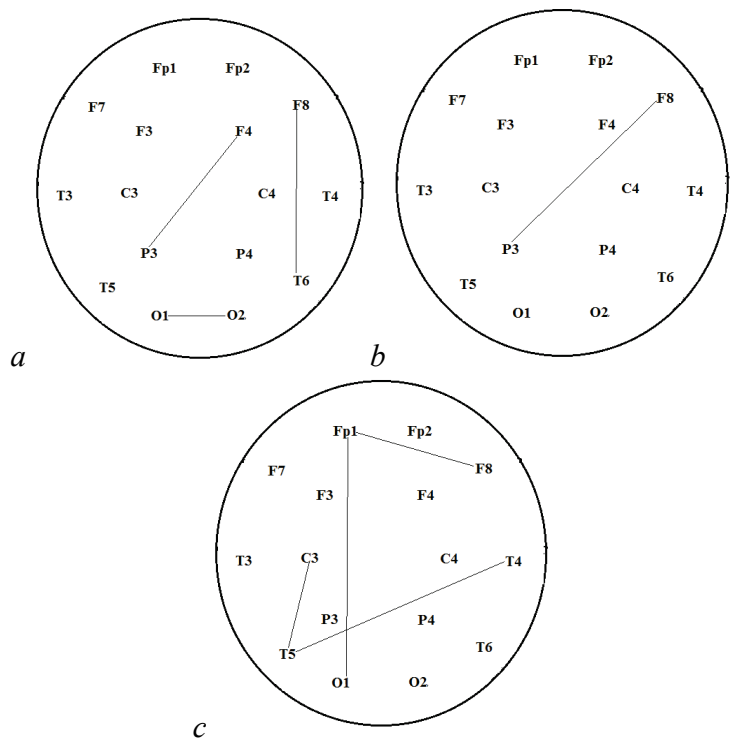

Fig. 8. Probable functional bonds of the cerebral cortex in the beta 2 range of the students $(\mathrm{n}=44): a$ - the usual memorization of foreign words compared with the background recording (open eyes); $b$ - the associative memorization of foreign words in comparison with the background recording (open eyes); $c$ - the associative memorization of foreign words in comparison with the usual way; thin line coherent bonds of average degree $(\mathrm{K}=0.60-0.69, \mathrm{P}<0.05)$, thick line - coherent bonds of high degree $(\mathrm{K}=0.70-0.95, \mathrm{P}<0.001)$

In associative thinking, unlike the usual one (Fig. 8c), there was an emergence of inter-hemispherical diagonal bonds (Fp1-F8; T4-T5) and the inner-hemispherical short bond (C3-T5) in the posterior part of the left hemisphere. In addition, the inner-hemispherical long bond in the left hemisphere between $\mathrm{Fpl}$ and $\mathrm{O} 1$ zones appeared.

\section{Discussion}

The process of information comprehension depends on its type (verbal or figurative) and the context of activity, but the prefrontal cortex is the key structure of the brain that always takes part in thinking. The domination of the left frontal and prefrontal cortex in generation of ideas and provision of purposeful information extraction from episodic and semantic memory (Razumnikova \& Finikov, 2011) is observed in our study.

Bilateral activation of the prefrontal cortex is associated with the visual-spatial strategy (Elfgren \& Risberg, 1998). Probably, when recalling the formed associations, the students performed spatial manipulations of unreal images. There is evidence that the direct reproduction of visual images from memory mainly depends on the back sections of the left hemisphere, and imaginary rotation and designing of the images mainly involves the structure of the posterior sections of the right hemisphere (Volf et al., 2009). Therefore, we can assume that the mention of associative images is reflected in the changes of power spectrum in the alpha-, delta- and theta-ranges. And the imaginary manipulation of images, according to our results, is reflected in the changes in the alphaand beta 2 -ranges. According to Luriya (2004), the parietal-occipital regions of the left hemisphere are responsible for the visual representation of the subject by its name. Occipital areas include the primary and secondary fields of the visual analyzer, parietal regions include secondary and tertiary associative fields. It is not by chance that we are witnessing the activation of these zones when mentioning associative information. The fact of the involvement of the temporal cortex areas in the implementation of working memory mechanisms, which was established by the well-known neurosurgeon Luriya (2004), is well known. The changes 
we observed in the power of fluctuations of the theta range of the EEG of the left temporal region (zone T5) may indicate an important role of the left temporal region in the processes of logical thinking, as pointed out in their research by Dzhebrailova et al. (2017). It is possible that the creation of associations involves this type of thinking, because associative images can be both absurd, characteristic of just one person, and quite logical. Consequently, we can assume that the use of mnemotechnics techniques led to the activation of associative logical connections and the rapid and correct reproduction of words, in contrast to the chaotic recollection of foreign words when not supported by figurative associations.

In their paper, Tarasova et al. (2005) show the connection between desynchronization of the theta-rhythm bi-potentials with the fulfillment of the tasks of a visual-spatial nature, which is connected with the inhibitory processes in information processing involving the cortico-hippocampal bonds. This is consistent with our results. Probably, the students in their imagination performed spatial manipulations with created associative images. According to the literature data, the theta-rhythm's power increases in response to cognitive load and reflects such nonspecific factors as overall level of attention, the level of complexity, and task-solving performance (Klimesch, 1999). The researchers associate the delta-fluctuations with the motivational component of brain activity and "internal" attention directed at solving the problem (Razumnikova \& Finikov, 2011). In addition, Fernindez et al. (1993) suggested that an increase in delta activity may be due to an increase in the internal concentration of subjects during the fulfillment of tasks, the complexity of the task and emotional factors demonstrated by the students during the usual memorization of foreign words. However, in comparison with the associative method of memorizing words with the usual method for the students, there was a decrease in power spectrum in both the delta and theta ranges, which can be explained by the reduced effort involved in reproducing associative information compared to recollecting foreign words without such support.

It is common knowledge that the largest amplitude of the alpha rhythm is achieved in a relaxed state, especially with closed eyes in a darkened room. In response to the opening of the eyes, there is a "disappearance" of $\alpha$-rhythm on the encephalogram (a phenomenon of desynchronization) (Bushov \& Svetlik, 2008). The assumption that the alpha rhythm amplitude decreases only as a result of light stimulation becomes doubtful when the opening of eyes in a completely dark room is also accompanied by a decrease in the amplitude of alpha-oscillations and not only in the visual cortex (Moosmann et al., 2003). Therefore, the alpha-amplitude reduction in the dark room happens not due to primary sensory stimulation, but more likely reflects the descending controlling effect of the cortex. It is also known that alpha activity is associated with sight, imagination and attention, and it is likely that the alpha-rhythm is blocked when working with imaginary visual images, which is consistent with our results (Yegorova, 1973; Robinson, 1983). It is suggested in Klimesch's research that reduction of alpha-amplitude, depending on the type of a task, is observed in the occipital and frontal sections of the brain, especially when processing semantic information (Klimesch et al., 1997; Klimesch, 1999). According to our data, alpha-activity in memorizing foreign words in both the usual and associative ways decreases, which is the reflection of the process of mental activity. It should be noted that the frontal areas of the cortex play an important role in the programming and decision-making processes, as many researchers have indicated, considering them as the brain substrate of different decisionmaking forms (Luriya, 2004; Bekhtereva \& Nagornova, 2007). In various studies, creative task performance was characterized by the cortex activation of the left hemisphere (the reduction of the $\alpha$-rhythm power in the frontal-temporal zones: Fp1, F3, F7). According to the model of the functional blocks (Luriya, 2004), the frontal zones of the cortex are responsible for making decisions, understanding the semantic content of a picture when it is viewed, and, quite possibly, when it is imagined.

In our study, there was a local desynchronization of the $\alpha$-rhythm in the posterior-temporal leads (T5 zone), which are closely related to the processes of imagination and prefiguration. Morenko (2012) indicates that the observed decrease in the power of $\alpha$ activity in the posterior frontal and temporal areas of the left hemisphere may indicate the use of cognitive and mnestic mechanisms for information processing, which is consistent with our results. It is believed that mental activity is accompanied by the development of fatigue. In the works of Cheng \& Hsu (2011); Lal \& Bekiaris (2007) it is stated that the development of this process is evidenced by an increase in power spectrum of alpha-rhythm in the parietal and occipital regions of the cerebral cortex. According to our data, no increase in the spectral power spectrum of the alpha-frequencies range was observed in the participants of the experiment. So we can conclude that the proposed task did not cause fatigue in the students because of the ease of performance and constant change of the studied words.

The role of beta-activity in cognitive and emotional processes is wellknown (Koryukalov, 2016). Beta-rhythm is associated with activation of the brain during various influences on reticular formation. In the studies of Klimesch $(1997,1999)$ it is shown that power increase in the lower beta ${ }_{1}$ range in the occipital and parietal cortical areas is associated with an increase in the effort that should be made by the subjects to maintain attention concentration during task fulfillment. In our experiment, there was no increase in power spectrum in the beta ${ }_{1}$-range, therefore, we can assume that memorizing of new foreign words by the proposed methods did not require excessive concentration of attention. The increase in the power of beta-frequencies in the EEG of the frontal areas is associated with their participation in the regulation of the active functional level and attention (Dan'ko, 2005), in the analysis of visual information and the processes of "non-verbal categorization" (Gusel'nikov, 1976), the reaction to new incentives (Krotin, 1971). In our case, the power of waves in the beta 2 ranged was reduced, hence, the memorization of the words was not associated with a high concentration of attention. With the use of the associative method in the process of memorizing foreign words, the images corresponding to each word are familiar to the imagination and do not require the search for new ways to create them. Thus, the study of biological terminology in English using the associative method is a more effective and simple way that does not cause fatigue and does not require excessive concentration of attention. An increase in the EEG synchronization in the delta-range of the occipital areas may indicate the retrieval of visual information from memory (Van Strien et al., 2005). The interaction in these areas of the right hemisphere, in the slow-wave range, may be explained by the reflection of the inner concentration of attention during the processing and manipulation of figurative information (Kozhedub et al., 2007). Also, the overall growth of synchronization at the delta frequency of EEG can be explained by inhibition of active attention to external stimuli, thereby the conditions for integration of individual elements in the imaginary creation of original and standard images are created. At the same time, concentration of attention is necessary in the mental process, in particular, when visualizing the manipulation of images (Goldman-Rakic et al., 1987). To accomplish such tasks, an action plan is implemented that includes the activation of certain cortical networks, their temporary organization in the source of synchronization and inhibition of motion programs (Decety \& Ingvar, 1990). Coherent bonds in the parietal, occipital and temporal regions of both hemispheres are the reflection of the activation of these zones when creating a three-dimensional visual information model, as a result of its perception, processing and transformation. It should be noted that in the literature the amplification of coherent relationships between potentials of theta-band of the EEG of the parietal-temporal-occipital regions of the cortex is traditionally associated with memory mechanisms, with the activation of the hippocampal structures (Raghavachari et al., 2006; Dzhebrailova \& Korobejnikova, 2013). The study conducted by Korobejnikova \& Dzhebrailova (2013) has shown that the distinctive feature of the physiological support of activity, which ends with the exact reproduction of the visual (in our case, figurative) information, is the enhancement of inter-hemispherical coherence in the range of the thetarhythm of the EEG. The emergence of long coherent connections in the theta-band let us suggest that when using the associative method of memorizing foreign words, the search for interconnections between imaginary images and their corresponding words occurs, and concentration of attention in the anteriofrontal and F7-P4 zones is increased. Simonov (1995) indicates that the theta-rhythm is an electrophysiological correlate that reflects the control of the extraction of memory engrams. The thetarhythm synchronization is also associated with the attention processes, which in our case are displayed in specific zones. The literature data show that with the development of the verbal-logical way of thinking, the brain 
transits into a special mode of functioning with a small number of functional bonds in the $\theta$-oscillations region, indicating the preservation of the pre-formed neural network (Tretiak et al., 2017). The coherent C3-C4 bond that we observed in the alpha-range is likely to indicate the creation of tactile, sensory images in the process of associative memorization. Zones C3-C4 are projection zones of the area of fingers, so we can assume that the creation of associations led not only to the visualization of images, but also to the implementation of imaginary motor manipulations with these images.

The work (Hebb, 1968) states that sensory visualization leads to the activation of higher cortical levels (sensory and abstract ones), which play an important role in the perception of the same images and events. At the same time, during the visualization of images, activation of "abstract" levels, even without the involvement of sensory modalities, occurs. Tretiak et al. (2017) in their study indicate that a higher manifestation of logical thinking increases the functional relationship of $\alpha$-waves in the central regions of the cerebral cortex. An increase in the potentials' coherence of the EEG $\alpha$-band of the posterior lower-frontal cortex regions, observed with the use of mnemotechnics, can be considered as the manifestation of the $\alpha$-system participation in the formation of the frontal-parietal network of selective endogenous attention, which selectively supports the active state of internal representations during the implementation of the working memory, in our case, the words encoded with the help of associations (Dzhebrailova et al., 2015). Numerous studies (Ingvar \& Philipsson, 1977; Roland et al., 1987; Roland \& Friberg, 1985; Decety \& Ingvar, 1990) show an activation of the anterior cortex during figurative thinking, which is consistent with our data. It should also be emphasized that the high level of coherence in the alpha-EEG region of the central regions of the cerebral cortex is attributed to the fact that these zones are projective for the ascending paths of a non-specific thalamic system that exhibits synchronizing effects on the brain cortex. Coherence in the alpha band of the EEG of the central and frontal cortex regions is also considered as an indicator of the influence of activating systems of the brain stem and subcortex (Rusinov et al., 1987). These facts let us suggest that a higher coherence in the system of inter-hemispherical and symmetrical inner-hemispherical bonds of the central, parietal and frontal areas may be due to more represented activating effects on the cortex by a non-specific thalamic system. In its turn, high coherence facilitates information interaction between the parietal and motor central, as well as parietal and frontal areas, contributing to faster decision-making and the choice of motion program (Dzhebrailova et al., 2011).

Let us note that during abstract memorizing of new words, alpha frequency synchronization is noted between the two hemispheres, indicating the involvement of both hemispheres in the process of storing the information obtained due to the creation of associations. The change in the spectral-coherent characteristics of the beta-rhythm is regarded as the correlate of various cognitive processes, attention and perception in particular. The enhancement of the local interaction of EEG beta biopotentials in the anterior-central regions of the brain is associated with the support of voluntary nonspecific attention and is considered as a component of working memory in adults (Dzhebrailova \& Korobejnikova, 2013). The increase in the synchronization of electrical activity in the beta-rhythm range is matched with information processing in the recognition of images (Palva et al., 2011). In addition, the literature contains information on increasing the coherence in the EEG beta 2 -range in intellectual activity (Razumnikova, 2005; Kozhedub et al., 2006). According to the data obtained, the synchronization in the beta-range, covering both hemispheres of the brain, is more represented in the left hemisphere, which is considered to be responsible for the processes of logical thinking. The most significant bonds are in the posterior regions of the left hemisphere, which indicates the use of analytical imaginative strategies in associative memorization. In the studies of Dzhebrailova \& Korobejnikova (2013), it was shown that during the reproduction of information, in the subjects, in comparison with the memorization stage and the initial state, the inter-hemispherical and preferably the left-sided intracavity coherence of the beta 2 potentials increased, which is consistent with our results. The growth of the number of inner-hemispherical bonds in the beta ${ }_{2}$ range with the imaginary creation of visual images is associated with a high level of passive attention, and the growth of inter-hemispherical coherence is associated with mobilization readiness for information processing by both hemispheres (Kozhedub et al., 2007). Consequently, we can conclude that the process of associative memorization is based on the creation of logical connections for the preservation of images. It is common knowledge that the corpus callosum plays a key role in ensuring attention concentration, as well as redistribution of attention when performing complex tasks (Hoptman \& Davidson, 1994). Short inter-hemispherical functional bonds between the symmetric leads indicate the transmission of information through the corpus callosum. According to the results of our research, most of the probable functional bonds passed through the corpus callosum, which probably contributed to the rapid analysis of images and words, easy memorization and the recollection of associative information.

\section{Conclusion}

The process of associative information memorizing is realized by reducing the power spectrum of the alpha range waves band in the frontal and temporal loci of the left hemisphere and the prefrontal sections of both hemispheres, which indicates the participation of these zones in the processes of preservation and reproduction of information which is memorized with the help of mnemotechnics. The probable decrease in the

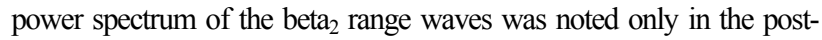
temporal locus of the right hemisphere. The changes in the delta range when mentioning the associative information were reflected in the reduction of power spectrum in a large number of zones of both hemispheres. In the theta range, the use of mnemotechnics has been reflected in the reduction of power spectrum in the prefrontal and posterior lower-frontal areas of both hemispheres, as well as in the posttemporal and occipital loci of the left hemisphere.

The processing of figurative information was reflected in the interaction of the occipital sections of the right hemisphere in the delta range. The reproduction of associative images and the corresponding attention concentration in the theta range were observed in the enhancement of the interhemispherical coherence of the anteriofrontal and F4-P4 zones. The presence of probable inter-hemispherical functional bonds, as well as the bonds between the symmetrical leads in the alpha and beta ranges, indicates the involvement of the corpus callosum in the processes of associative images reproduction, which contributed to the rapid, correct and easy recollection of foreign words that were memorized with the help of mnemonic techniques, in contrast to the chaotic recollection of foreign words when not supported by figurative associations.

\section{References}

Bechtereva, N. P., \& Nagornova, Z. V. (2007). Changes in EEG coherence during tests for nonverbal (Figurative) creativity. Human Physiology, 33(5), 515-523.

Bushov, Y. V., \& Svetlik, M. V. (2008). Vysokochastotnaya elektricheskaya aktivnost' mozga i kognitivnyye protsessy [High-frequency electrical brain activity and cognitive processes]. Tomskiy Gosudarstvennyy Universitet, Tomsk (in Russian).

Cheng, S. Y., \& Hsu, H. T. (2011). Mental fatigue measurement using EEG. In: Giancarlo, N. (Ed.). Risk management trends. InTech, Rijeka. Pp. 203-228.

Craik, F. M., \& Lockhart, R. S. (1972). Levels of processing: A framework for memory research. Journal of Verbal Learning and Verbal Behaviour, 11, $671-684$.

Dan'ko, S. G. (2005). Elektroentsefalograficheskiye korrelyaty sostoyaniy mozga pri verbal'nom obuchenii [Electroencephalographic correlates of the brain state during verbal learning]. Fiziologiya Cheloveka, 31(5), 15-20 (in Russian).

Decety, J., \& Ingvar, D. H. (1990). Brain structures participating in mental simulation of motor behavior: A neurophysiological interpretation. Acta Psychologica, 73(1), 13-34.

Dresler, M., \& Konrad, B. N. (2013). Mnemonic expertise during wakefulness and sleep. Behavioral and Brain Sciences, 36(6), 616-617.

Dresler, M., Shirer, W. R., Konrad, B. N., Müller, N. J., Wagner, I. C., Fernández, G., Czisch, M., \& Greicius, M. D. (2017). Mnemonic training reshapes brain networks to support superior memory. Neuron, 93(5), 1227-1235.

Dzhebrailova, T. D., \& Korobejnikova, I. I. (2013). Prostranstvennaja organizacija beta2-ritma EEG i effektivnost' kognitivnoj dejatelnosti cheloveka [Spatial organization of the beta2-rhythm and the effectiveness of human cognitive activity]. Zhurnal Vysshej Nervnoj Dejatelnosti, 63(6), 667-676 (in Russian). 
Dzhebrailova, T. D., Korobejnikova, I. I., Karatygin, N. A., \& Dudnik, E. N. (2015). Dynamics of EEG $\alpha$ activity and heart rate variability in subjects performing cognitive tests. Human Physiology, 41(6), 599-610.

Dzhebrailova, T. D., Korobejnikova, I. I., Karatygin, N. A., \& Umrjuhin, E. A. (2011). Prostranstvennaja organizacija biopotencialov kory golovnogo mozga i vremja prinjatija reshenija pri celenapravlennoj intellektual'noj dejatel'nosti cheloveka [Spatial organization of the cerebral cortex biopotentials and decision - making time for targeted intellectual human activity]. Zhurnal Vysshej Nervnoj Dejatelnosti, 61(2), 180-189 (in Russian).

Dzhebrailova, T. D., Korobeynikova, I. I., Karatygin, N. A., \& Dudnik, Y. N. (2017). Vzaimosvyaz' parametrov teta i beta-aktivnosti EEG i variabel'nosti serdechnogo ritma pri intellektual'noy deyatel'nosti cheloveka [Interrelation of EEG theta- and beta-activity parameters and heart rate variability in human intellectual activity]. Fiziologiya Cheloveka, 43(2), 91-105 (in Russian)

Eichenbaum, H. (2017). Memory: Organization and control. Annual Review of Psychology, 68, 19-45.

Elfgren, C. I., \& Risberg, J. (1998). Lateralized frontal blood flow increases during fluency tasks: Influence of cognitivestrategy. Neuropsychology, 36, 505-512.

Fellner, M. C., Volberg, G., Wimber, M., Goldhacker, M., Greenlee, M. W., \& Hanslmayr, S. (2016). Spatial mnemonic encoding: Theta power decreases cooccur with medial temporal lobe bold increases during the usage of the method of loci. Eneuro, 3(6), e0184

Fernindez, T., Harmony, T., Rodriguez, M., Reyes, A., Marosi, E., \& Bernal, J. (1993). Test-retest reliability of EEG spectral parameters during cognitive tasks. I. Absolute and relative power. International Journal of Neuroscience, $68,255-261$.

Goldman-Rakic, P. S., Mountcastle, V. B., Plum, F., \& Geiger, S. G. (1987). Circuitry of primate prefrontal cortex and regulation of behavior by representational memory. Comprehensive Physiology, 5, 373-417.

Greicius, M. D., Krasnow, B., Reiss, A. L., \& Menon, V. (2003). Functional connectivity in the resting brain: A network analysis of the default mode hypothesis. Proceedings of the National Academy of Sciences, 100(1), 253-258.

Gusel'nikov, V. I. (1976). Elektrofiziologiya golovnogo mozga [Brain electrophysiology]. Prosveshcheniye, Moscow (in Russian).

Hampstead, B. M., Stringer, A. Y., Stilla, R. F., \& Sathian, K. (2019). Mnemonic strategy training increases neocortical activation in healthy older adults and patients with mild cognitive impairment. International Journal of Psychophysiology, S0167-8760(18), 30904-30908.

Hebb, D. O. (1968). Concerning imagery. Psychological Review, 75(6), 466- 477.

Hoptman, M. J., \& Davidson, R. J. (1994). How and why do the two cerebral hemispheres interact? Psychological Bulletin, 166(2), 195-219.

Ingvar, D. H., \& Philipsson, L. (1977). Distribution of cerebral blood flow in the dominant hemisphere during motor ideation and motor performance. Annals of Neurology, 2(3), 230-237.

Jeffrey, P. B. (2017). Mnemonic strategies: Helping students with intellectual and developmental disabilities remember important information. Global Journal of Intellectual and Developmental Disabilities, 2(3), 555-587.

Klimesch, W. (1997). EEG-alpha rhythms and memory processes. International Journal of Psychophysiology, 26, 319-340.

Klimesch, W. (1999). EEG alpha and theta oscillations reflect cognitive and memory performance: A review and analysis. Brain Research Reviews, 29, 169-195.

Klimesch, W., Doppelmayr, M., Pachinger, T., \& Russegger, H. (1997). Eventrelated desynchronization in the alpha band and the processing of semantic information. Cognitive Brain Research, 6, 83-94.

Korobejnikova, I. I., \& Dzhebrailova, T. D. (2013). Spektral'no-kogerentnye harakteristiki teta-ritma EEG cheloveka pri razlichnoj effektivnosti zapominanija zritel'noj informacii [Spectral and coherent characteristics of a person's EEG theta rhythm with different efficacy of memorizing visual information] Akademicheskij Zhurnal Zapadnoj Sibiri, 9(4), 76-77 (in Russian).

Kozhedub, R. G., Sviderskaja, N. E., \& Taratynova, G. V. (2006). Prostranstvennaja organizacija biopotencialov i original'nost' zritel'nyh obrazov [Spatial organization of biopotentials and originality of visual images]. Zhurnal Vysshej Nervnoj Dejatelnosti, 56(4), 437-446 (in Russian)

Lopatin, M. A. (2014). Mnemonicheskiye priyomy v obuchenii inoyazychnoy leksike [Mnemonic techniques in teaching of innovative lexics]. Filologicheskiye Nauki, Voprosy Teorii i Praktiki, 32, 105-109 (in Russian).

Maguire, E. A., Valentine, E. R., Wilding, J. M., \& Kapur, N. (2003). Routes to remembering: The brains behind superior memory. Nature Neuroscience, $6(1), 90-95$

Mastropieri, M. M. (1988). Using the keyword method. Teaching Exceptional Children, 20(2), 4-8.

Montembeault, M., Chapleau, M., Jarret, J., Boukadi, M., Laforce, R. J., Wilson, M. A., Rouleau, I., \& Brambati, S. M. (2019). Differential language network functional connectivity alterations in Alzheimer's disease and the semantic variant of primary progressive aphasia. Cortex, 117, 284-298.

Moosmann, M., Ritter, P., Krastel, I., Brinka, A., Theesa, S., Blankenburga, F., Taskina, B., Obriga, H., \& Villringera, A. (2003). Correlates of alpha rhythm in functional magnetic resonance imagingand near infrared spectroscopy. NeuroImage, 20, 145-158.

Morenko, A. G. (2012). Elektrofiziologichni koreljaty funkcional'nyh staniv, pov'jazanyh iz fonostymuljacijeju ta sluhomotornoju dijal'nistju u cholovikiv [Electrophysiological correlates of functional states associated with phonostimulation and auditory-motor activity of males]. Visnyk of Dnipropetrovsk University, Biology, Medicine, 3(1), 152-161 (in Ukrainian)

Palva, S., Kulashekhar, S., \& Palva, J. M. (2011). Localization of cortical phase and amplitude dynamics during visual working memory encoding and retention. Journal of Neuroscience, 31(13), 5013-5025

Pfurtscheller, G., \& Lopes da Silva, F. N. (1999). Event-related EEG-MEG synchronization and desynchronization: Basic principles. Clinical Neurophysiology, 110(11), 1842-1857.

Raghavachari, S., Lisman, J. E., Tully, M., Madsen, J. R., \& Bromfield, E. B. (2006). Theta oscillations in human cortex during a working memory task: evidence for local generators. Neurophysiology, 95(3), 1630-1638

Razumnikova, O. M. (2005). Chastotno-prostranstvennaja organizacija aktivnosti kory mozga pri konvergentnom i divergentnom myshlenii v zavisimosti of faktora pola: Soobshhenie II. Analiz kogerentnosti EEG [Frequency-spatia organization of cerebral cortex activity during convergent and divergent thinking depending on the gender factor: Message II. Coherence analysis of EEG]. Fiziologija Cheloveka, 31(3), 39-49 (inRussian).

Razumnikova, O. M., \& Finikov, S. B. (2011). Otrazheniye sotsial'noy kreativnostiv osobennosty akhaktivnosti korynachastotakh del'ta-, al'fa ${ }_{2}$ i gamma $2_{-}$ ritmov [Reflection of social creativity in the peculiarities of cortex activity at the frequencies of delta-, alpha $2_{2}$ and gamma ${ }_{2}$ - rhythms]. Zhurnal Vysshej Nervnoj Dejatelnosti, 61(6), 706-715 (in Russian).

Rebrova, O. J. (2014). Statisticheskij analiz medicinskih dannyh. Primenenie paketa prikladnyh programm Statistica [Statistical analysis of medical data. The use of Statistica application programs package]. Dental Science and Practice, 1, 43-47 (in Russian).

Robinson, D. (1983). Analysisof human EEG responses in the alpha range of frequencies. International Journal of Neuroscience, 22, 81-98.

Roland, E., Ericksson, S., Stone-Elander, S., \& Widen, L. (1987). Doesmental activity change the oxidative metabolism of the brain'? Trends in Neurosciences, 7, 430-435.

Roland, P. E., \& Friberg, L. (1985). Localization of cortical areas activated by thinking. Journal of Neurophysiology, 53, 1219-1243.

Schacter, D. L., Addis, D. R., \& Buckner, R. L. (2007). Remembering the past to imagine the future: The prospective brain. Nature Reviews Neuroscience, $8(9), 657-661$

Seeley, W. W., Crawford, R. K., Zhou, J., Miller, B. L., \& Greicius, M. D. (2009) Neurodegenerative diseases target large-scale human brain networks. Neuron, $62(1), 42-52$

Simon, S. S., Hampstead, B. M., Nucci, M. P., Duran, F. S., Fonseca, L. M., Martin, M. M, Ávila, R., Porto, F. G., Brucki, S. D., Martins, C. B., Tascone, L. S., Amaro, E. J., Busatto, G. F., \& Bottino, C. C. (2019). Training gains and transfer effects after mnemonic strategy training in mild cognitive impairment: A fMRI study. International Journal of Psychophysiology, S01678760(18), 30961-30969.

Simonov, P. V. (1995). Nejrobiologicheskie osnovy kreativnosti [Neurobiological basis of creativity]. Fiziologija Cheloveka, 21(2), 1-9 (in Russian).

Tarasova, I. V., Vol'f, N. V., \& Razumnikova, O. M. (2005). Izmeneniya moshchnosti EEG pri obraznom kreativnom myshlenii u muzhchin i zhenshchin [Changes in the power of EEG in imaginative creative thinking of males and females]. Zhurnal Vysshej Nervnoj Dejatelnosti, 55(6), 780-784 (in Russian).

Thaut, M. H., Peterson, D. A., McIntosh, G. C., \& Hoemberg, V. (2014). Music mnemonics aid verbal memory and induce learning-related brain plasticity in multiple sclerosis. Frontiers in Human Neuroscience, 8, 395.

Tretiak, T. O., Sokorenko, A. G., Dregval, I. V., \& Severynovska, O. V. (2017). Analysis of brain bioelectric activity during verbal-logical thinking of biology students. Regulatory Mechanisms in Biosystems, 8(2), 244-251.

Van Strien, J. W., Hagenbeek, T. E., Stam, C. J., Rombouts, S., \& Barkhof, F. (2005). Changes in brain electrical activity during extended continuous word recognition. Neurolmage, 26, 952-959.

Vincent, J. L., Snyder, A. Z., Fox, M. D., Shannon, B. J., Andrews, J. R., Raichle, M. E., \& Buckner, R. L. (2006). Coherent spontaneous activity identifies a hippocampal-parietal memory network. Journal of Neurophysiology, 96(6), 3517-3531.

Vol'f, N. V., Tarasova, I. V., \& Razumnikova, O. M. (2009). Polovyye razlichiya $\mathrm{V}$ izmeneniyakh kogerentnosti biopotentsialov kory mozga pri obraznom tvorcheskom myshlenii: Svyaz' s effektivnost'yu deyatel'nosti [Sexual differences in the coherence changes of cerebral cortex biopotentials in imaginative creative thinking: the connection with operational efficiency]. Zhurnal Vysshej Nervnoj Dejatelnosti, 59(4), 429-436 (in Russian).

Worthen, J. B., \& Hunt, R. R. (Ed.). (2011). Mnemonology: Mnemonics for the 21st century. Psychology Press, New York. 